\title{
Emerging Roles of DDB2 in Cancer
}

\author{
Pauline Gilson ${ }^{1}$, Guillaume Drouot ${ }^{2}$, Andréa Witz ${ }^{1}{ }^{\mathbb{D}}$, Jean-Louis Merlin ${ }^{1}$, Philippe Becuwe ${ }^{2}$ \\ and Alexandre Harlé ${ }^{1, *}$ (D) \\ 1 Institut de Cancérologie de Lorraine, Service de Biopathologie, Université de Lorraine, CNRS UMR \\ 7039 CRAN, 54519 Vandœuvre-lès-Nancy CEDEX, France; p.gilson@nancy.unicancer.fr (P.G.); \\ a.witz@nancy.unicancer.fr (A.W.); jl.merlin@nancy.unicancer.fr (J.-L.M.) \\ 2 Faculté des Sciences et Technologies, Université de Lorraine, CNRS UMR 7039 CRAN, \\ 54506 Vandœuvre-lès-Nancy CEDEX, France; guillaume.drouot@orange.fr (G.D.); \\ philippe.becuwe@univ-lorraine.fr (P.B.) \\ * Correspondence: a.harle@nancy.unicancer.fr; Tel.: +33-383656119
}

Received: 23 September 2019; Accepted: 15 October 2019; Published: 18 October 2019

\begin{abstract}
Damage-specific DNA-binding protein 2 (DDB2) was originally identified as a DNA damage recognition factor that facilitates global genomic nucleotide excision repair (GG-NER) in human cells. DDB2 also contributes to other essential biological processes such as chromatin remodeling, gene transcription, cell cycle regulation, and protein decay. Recently, the potential of DDB2 in the development and progression of various cancers has been described. DDB2 activity occurs at several stages of carcinogenesis including cancer cell proliferation, survival, epithelial to mesenchymal transition, migration and invasion, angiogenesis, and cancer stem cell formation. In this review, we focus on the current state of scientific knowledge regarding DDB2 biological effects in tumor development and the underlying molecular mechanisms. We also provide insights into the clinical consequences of DDB2 activity in cancers.
\end{abstract}

Keywords: DDB2; DNA repair; cancers; proliferation; migration; invasion

\section{Introduction}

DDB2 (damage-specific DNA-binding protein 2, also known as p48 subunit) is a 48-kDa protein exclusively localized in the nucleus of mammalian cells. DDB2 is ubiquitously present in human tissues, albeit differentially expressed. High DDB2 expression level has been described in liver, thymus, kidney, and testes, and a low expression level has been described in brain, lung, skin, heart, and muscles [1]. DDB2 is composed of seven WD40 repeat domains and a $N$-terminal helix-loop-helix motif [2]. The WD40 domains play a role as a module for sequence-specific protein-DNA or protein-protein interactions. Both domains appear critical for the biological functions of DDB2.

Numerous overlapping mechanisms have been found to be involved in the regulation of DDB2 expression. DDB2 basal expression is cell cycle-dependent in normal dividing cells with a DDB2 level that gradually increases in the mid-G1 phase and reaches a maximum at the G1/S boundary before dropping in the S-phase [3]. DDB2 transcription was shown to be transiently increased after UV-induced DNA damage in a p53-dependent manner [1]. The p53 protein cooperates with BRCA1 (Breast Cancer Associated protein 1) for its binding to the $d d b 2$ promoter and inducing $d d b 2$ transactivation [1] (Figure 1). The TAp63 $\gamma$ (Tumor protein 63 isoform gamma) isoform of the p63 protein that belongs to the p53 family and shares strong structural similarity with p53 is also able to activate DDB2 expression through recognition of the same region upstream of the transcription initiation site [4]. Structural analysis of the $d d b 2$ promoter shows multiple Sp1 (Transcription factor $\mathrm{Sp} 1)$-specific binding sites as usually found in gene promoters with a $\mathrm{G}-\mathrm{C}$ rich sequence lacking a TATA box and suggesting a critical role for Sp1 for the basal expression of DDB2 [5] (Figure 1). NF1 
(Neurofibromin 1) and E2F (Transcription factor E2F) elements are also identified, although probably having a smaller impact on DDB2 regulation [5]. Moreover, DDB2 activity is finely adjusted through post-transcriptional and post-translational mechanisms. An IRES (internal ribosome entry site) element located at the $5^{\prime}$ end of DDB2 mRNA stimulates the translational process of DDB2 in stress conditions such as serum starvation or exposure to doxorubicin [6]. Moreover, the $3^{\prime}$ untranslated region (3'UTR) of DDB2 mRNA harbors an uracil-rich sequence enabling its prompt export to the cytoplasm and thus DDB2 translational upregulation. During the DNA repair process, the Cul4A (Cullin4A) protein regulates DDB2 protein lifespan by means of its ubiquitin ligase functions [3]. The PARylation (Protein poly ADP-ribosylation) of the DDB2 protein in a PARP1-dependent (Poly [ADP-ribose] polymerase 1) manner stabilizes DDB2 and delays its degradation [7]. A PIP (PCNA-interacting protein) box sequence located in the $N$-terminal region of DDB2 enables the interaction between DDB2 and PCNA (proliferating cell nuclear antigen) for DDB2 proteolytic degradation even in the absence of DNA damage $[8,9]$.

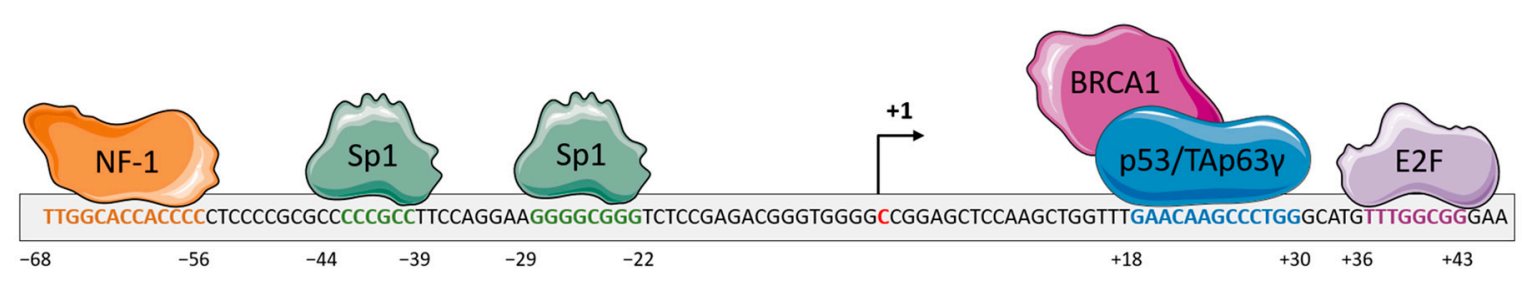

Figure 1. Schematic representation of the regulation of the gene encoding the DDB2 (Damage-specific DNA-binding protein 2) protein. The proximal promoter of $d d b 2$ gene harbors response elements for the transcription factors NF-1 (Neurofibromin 1) (orange) and Sp1 (Transcription factor Sp1) (green) upstream of the transcription initiation site. The proximal promoter also contains a response element for p53, in association with BRCA1 (Breast cancer type 1 susceptibility protein), or Tap63 $\gamma$ (Tumor protein 63 isoform gamma) (blue) proteins and the E2F (Transcription factor E2F) transcription factor downstream of the transcription initiation site. The binding of these proteins leads to the regulation of $d d b 2$ gene expression.

DDB2 was originally identified as a component of the UV-DDB human damage-specific DNA-binding heterodimeric complex along with DDB1 (damage-specific DNA-binding protein 1, also named p127 subunit) [2]. The X-ray structure of the UV-DDB complex showed that the interaction between DDB1 and DDB2 is mediated by the contact between the helix-loop-helix domain of DDB2 and two short repetitive $\beta$-propeller domains (WD40) of DDB1 [2]. UV-DDB forms a larger complex through the association of the DDB1 adaptor with the CRL ((CUL4A)-Regulator of Cullins-1 (ROC1 or RBX1) E3 ubiquitin ligase) complex [10]. In this structure, DDB1 serves as an adaptor molecule while DDB2 functions as a substrate receptor module that determines the specificity of targeted substrate [10]. DDB2 locally recognizes DNA damage sites and initiates the global genome nucleotide excision repair process (GG-NER) [2]. DDB2 specifically binds to the most frequent UV-damaged DNA lesions including (6-4) pyrimidine-pyrimidone photoproducts (6-4PPs) and cyclobutane pyrimidine dimers (CDPs) and appears essential for the repair of this latter [11]. The WD40 motifs of DDB2 facilitate the access of XPC (Xeroderma Pigmentosum group C) and other repair proteins to DNA lesions through histone modifications and chromatin decondensation that weaken DNA-histones interactions [10,12,13]. DDB2 fulfils this function through the recruitment of poly(ADP-ribose) polymerases (PARP) that append several units of ADP-ribose on histones [7]. As a part of the NER system, DDB2 also contribute to the repair of bulky DNA adducts other than UV-induced ones. For example, DDB2 was shown to recognize many forms of DNA damages, including those induced by platin-derived products, nitrogen mustard, psoralen, abasic sites, as well as single-stranded DNA [14]. However, less is known about the specific role of DDB2 in the repair of these DNA damages.

Beyond its most-studied role in DNA repair pathways, DDB2 appears as a multifunctional protein that participates in other essential biological processes such as gene transcription, cell cycle 
progression, and protein degradation. Since DDB2 exhibits chromatin-remodeling functions, DDB2 has come to be recognized as a transcription regulator for a wide range of target genes. DDB2 especially participates in the activation of SWI/SNF (SWItch/Sucrose Non Fermenting) remodeling complexes [15] as well as STAGA (SPT3-TAFII31-GCN5L acetylase) and CBP (CREB (cAMP-response-element-binding protein)-binding protein)/p300histone acetyltransferase complexes [16] that contribute to chromatin unfolding and facilitate the recruitment of RNA polymerase to specific regions. DDB2 also stimulates the transcriptional activity of the transcription factor E2F1 and thus the expression of multiple target genes involved in cell cycle progression [3]. As a recognized member of the DDB1 and CUL4-associated factors (DCAF), DDB2 is in a close contact with the E3 ubiquitin ligase of the Cul4A protein and hence participates in the degradation of various proteins such as the cyclin-dependent kinase (CDK) inhibitor p27, a well-known negative regulator of the cell cycle [17]. DDB2 also contributes to the decay of p53 protein to maintain low levels of the CDK inhibitor $\mathrm{p} 21^{\text {Waf1/Cip1 }}$ [18].

Several studies reported DDB2 as playing a novel function in the development and progression of various cancers. Herein, we focus on the current state of scientific knowledge regarding the biological effects of DDB2 in tumor development and the underlying molecular mechanisms. We also provide insights into the clinical consequences of DDB2 activity in cancers.

\section{DDB2: A New Potent Tumor Suppressor?}

DDB2 was first considered as a novel tumor suppressor based on the findings that mutations in the ddb2 gene result in an impairment in DDB2-DNA or DDB2-DDB1 interactions and subsequent NER activity defects [2]. Such deficiencies are observed in a subset of Xeroderma pigmentosum hereditary disease (Xeroderoma pigmentosum group E, XP-E) that displays an extreme sensitivity to UV radiation and a high predisposition to skin cancers [7]. Moreover, DDB2-deficient mice are prone to developing a wide panel of tumors, even in the absence of UV exposition [19]. Several studies highlighted an altered DDB2 expression, compared to non-malignant tissues, in many types of cancers [20], including prostate [21], colorectal [22,23], skin [24], head and neck [25], and ovarian [26] cancers. Furthermore, a correlation between low DDB2 expression level and poor outcomes was established among patients with melanoma, colon, ovarian, lung, breast, brain or head, and neck cancers, suggesting a critical role for DDB2 in tumor suppression [22,25-27].

\section{DDB2 Has a Dual Activity on Cancer Cell Proliferation}

High levels of DDB2 protein and mRNA are reported in ER (Estrogen receptor)-positive and non-invasive breast cancer models compared to ER-negative aggressive breast cancer cells and mammary non-malignant cells [16]. Enhanced DDB2 expression in DDB2-low level models upregulates in vitro cancer cell growth rate and clonogenicity. Such effects are abrogated by DDB2 knockdown in DDB2-overexpressed breast cancer models, suggesting the oncogenic role of DDB2 in mammary cancer cell growth [16]. DDB2 facilitates cell cycle progression, especially the entry in the S-phase, through the binding of the C-terminal domain and the co-activation of the transcription factor E2F1 [3]. By means of E2F1 transcriptional abilities, DDB2 indirectly regulates the expression of key genes involved in DNA replication and G1/S transition. The stimulating effect of DDB2 on cancer cell growth also involves the downregulation of manganese superoxide dismutase (MnSOD) [16]. MnSOD is a mitochondrial enzyme that detoxifies reactive oxygen species (ROS) to protect cells from oxidative damage. DDB2 interacts with the proximal SOD2 (Superoxide dismutase 2) promoter, resulting in the loss of $\mathrm{H} 3$ histone acetylation, and in the recruitment of the AP-2 transcription factor, which is well known in the repression of the SOD2 gene and downregulation of the encoded MnSOD [28]. By this mechanism, DDB2 attenuates the elimination of ROS that are known to activate several signaling pathways involved in breast cancer cell growth [28].

In contrast, DDB2 has shown antiproliferative properties in ovarian and prostate cancers in vitro. In an ovarian cancer cell model, DDB2 is reported to negatively regulate NEDD4L (Neural precursor cell expressed developmentally downregulated gene 4-like) cellular levels by inducing histone $\mathrm{H} 3$ 
trimethylation at the NEDD4L promoter region [29]. This limits the NEDD4L-dependent proteolytic degradation of the effector proteins SMAD2 (Mothers against decapentaplegic homolog) and SMAD3 and enhances the TGF- $\beta$ (Transforming growth factor beta) signal transduction downstream, finally contributing to the inhibition of cancer cell proliferation [29].

NRIP/DCAF6 (Nuclear receptor-interacting protein 1/DDB1- and CUL4-associated factor 6) and DDB2 proteins are both members of the DDB1 and CUL4-associated factors DCAF family and androgen receptor (AR)-interacting proteins that physiologically compete to maintain AR expression level. DDB2 mediates the contact between AR and CUL4A-DDB1 E3 ligase complex for AR ubiquitination and proteasomal degradation in a p53-independent manner [30], while NRIP displaces DDB2 from the complex and stabilizes AR [21]. As the DDB2 expression level is found to be lower in prostate cancer tissues compared to non-neoplastic ones, this could interfere with AR homeostasis and induce subsequent AR-dependent prostate cancer growth.

Deregulation in the Wnt signaling pathway is usually co-opted during colon cancer development and is sought to be a driver event in this process. Negative regulatory effects of DDB2 in the Wnt signaling are mediated by the recruitment of $\beta$-catenin and the H3K27 methylase EZH2 (Enhancer of zeste homolog 2) to Rnf43 (Ring Finger protein 43) promoter. This facilitates the activation of the RNF43 enzyme that eliminates Wnt receptors at the cell surface and downregulates Wnt signaling in colorectal cancer cells [31].

\section{DDB2 Confers Resistance to Radiation and PARP Inhibitors and Sensitizes Cancer Cells to Chemotherapy-Induced Apoptosis}

DDB2 participates in cellular responses to radiation-induced DNA damages [32]. Upon ionizing radiations, the DDB2 level transiently increases and facilitates homologous recombination repair of DNA double-strand breaks and prevents apoptosis. This is mediated by the phosphorylation of the G2-arrest-mediating factor Chk1 and confers radioresistance in the NSCLC (Non-small-cell lung carcinoma) cell model. A recent study shows that DDB2 also protects triple negative breast cancer cells from PARP inhibition and apoptosis through the regulation of DNA double-strand break repair by homologous recombination pathway [33]. DDB2 deficiency could thus sensitize TNBC cells to PARP inhibitors.

Given the role of DDB2 in DNA repair pathways, it could be argued that tumors with DDB2 deficiency should be more sensitive to DNA damaging treatments, such as platin products, as they lack some repair. However, DDB2 activity seems not needed to repair cisplatin-induced DNA crosslinks [34]. Besides, DDB2 participates in sensitizing ovarian cancer cells to cisplatin-mediated apoptosis through the downregulation of the $b c l-2$ (B-cell lymphoma 2) transcriptional machinery in a HDAC1-dependent (Histone deacetylase 1) manner and the ubiquitylation of the antiapoptotic protein bcl-2 [34].

In the context of NER, DDB2 has a significant role in apoptotic processes through the regulation of p53 activity [35]. Upon exposure to DNA-damaging agents, DDB2-deficient cells fail to undergo apoptosis due to the implication of DDB2 as a member of the UV-DDB complex in the degradation of the CDK (cyclin-dependent kinase) inhibitor p21 Waf1/Cip1 [20]. In case of DDB2 depletion, p21 Waf1/Cip1 accumulates in cells associated with a blockade of apoptosis and cell cycle arrest. Cisplatin-resistant Hela cells are found to survive UV-induced apoptosis due to the accumulation of DDB2 associated with the upregulation of the antiapoptotic protein c-Flip (Cellular FLICE-like inhibitory protein) [36].

\section{DDB2 Influences Epithelial to Mesenchymal Transition (EMT) and Cancer Cell Migration and Invasion}

Several studies reported DDB2 as a negative regulatory factor of cancer cell migration and invasion. This notion is supported by the findings that DDB2 associates with the NFKBIA (NFKB Inhibitor Alpha) promoter region and enhances the expression of the encoded protein $\mathrm{I} \kappa \mathrm{B} \alpha$ (nuclear factor of kappa light polypeptide gene enhancer in B-cells inhibitor, alpha), a cytoplasmic inhibitor of NF- $\mathrm{kB}$ (nuclear factor $\mathrm{kB}$ ) [28]. Thus, DDB2 may reduce the NF- $\mathrm{KB}$ activity and its associated cancer-invasion effects in 
breast cancers. DDB2 also modulates nanomechanical properties and stiffness of the mammary cancer cells associated with changes in the cortical actin-cytoskeleton organization and a loss of adhesion capacity [37].

DDB2 also represses head and neck squamous cell carcinoma and colon cancer progression by recruiting the histone H3K9 methylase suv39h (suppressor of variegation 3-9 homolog 1) to limit the transcriptional activity of Snail and ZEB1 (Zinc finger E-box Binding homeobox 1) factors and their epithelial-to-mesenchymal functions [25]. Upregulation of DDB2 levels induces the conversion of colon cancer cells with mesenchymal-type to epithelial-type. Conversely, the depletion of DDB2 in epithelial-type cells induces a morphological change in these cells with the appearance of mesenchymal characteristics. In the same way, DDB2 restricts the transcription of the pro-angiogenic growth factor VEGF (vascular endothelial growth factor) [25] and thus contributes to the inhibition of cancer cell invasion and metastasis formation.

However, another recent study suggests that DDB2 exerts migration and invasion stimulatory functions in gastric cancers. It reveals that DDB2 promotes the ubiquitination and degradation of a newly identified tumor suppressor PAQR3 (progestin and adipoQ receptor family member III) that limits cancer development and progression, notably inhibiting cancer cell migration, invasion, and angiogenesis [38].

\section{DDB2 Affects Cancer Stem Cell Populations}

Some studies reveal the protective role of DDB2 for ovarian cancer progression and recurrence by limiting the cancer stem cell (CSC) population. High levels of DDB2 are shown to halt the formation of ovarian tumor xenografts in vivo [26]. DDB2 exerts this regulatory function through the increase of I $\mathrm{B} \alpha$ protein levels, which results in the repression of the NF- $\mathrm{kB}$ signaling pathway and impinges the capacity of CSC to self-renew [26]. DDB2 also represses ovarian cancer cell dedifferentiation by inhibiting the transcription of aldehyde dehydrogenase 1 family member A1 (ALDH1A1) [39]. The impact of DDB2 on cancer stem cell populations is still under investigation in other cancer models and need to be explored.

\section{Concluding Remarks and Perspectives}

DDB2 was originally identified as a sensor of DNA damage that plays a critical role in DNA repair pathways. Sequence-specific interactions of DDB2 with DNAs or proteins make it a multifunctional protein with various functions in chromatin remodeling, gene transcription, cell cycle progression, and protein decay. More recently, the emerging role of DDB2 in the regulation of carcinogenesis has been established. DDB2 was first considered as a new tumor suppressor based on the finding that DDB2 deficiency leads to tumor formation. However, growing evidence about DDB2 activity suggests a regulatory mode more complex than envisioned. Actually, DDB2 seems to have a dual function in cancers, sometimes having tumor-suppressive properties and sometimes functioning as an oncogene. DDB2 exerts multilevel regulation of cancer development and progression, modulating cancer cell growth, migration and invasion, angiogenesis, and CSC formation (Figure 2)

These data suggest that DDB2 may have a potent role as a prognosis and predictive biomarker in cancers. However, they emphasize the need to improve our knowledge on DDB2 functions in the different cancer types, owing to the fact that DDB2 behaves differently according to cancer localization (Figure 3). Considering the importance of DDB2 in cancers, it becomes crucial to better understand its regulation and expression. The potent role of DDB2 as a direct or indirect drug target for the management of patients with cancer needs to be investigated. 


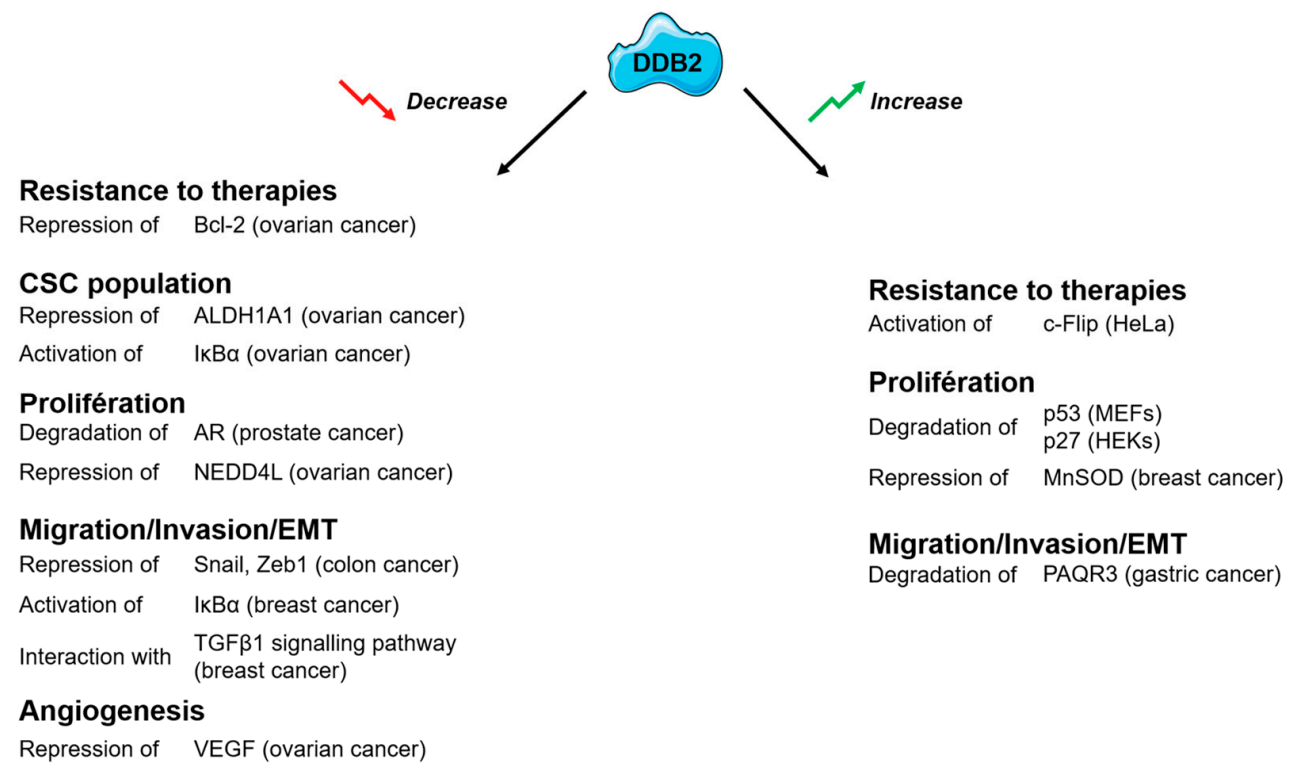

Figure 2. Roles of the DDB2 (Damage-specific DNA-binding protein 2) protein and its identified partners. AR (Androgen Receptor), ALDH1A1 (Aldehyde dehydrogenase 1 family, member A1), Bcl-2 (B-cell lymphoma 2), c-Flip (Cellular FLICE-like inhibitory protein, EMT (Epithelial-mesenchymal transition), HEKs (Human epidermal keratinocytes), IкB $\alpha$ (nuclear factor of kappa light polypeptide gene enhancer in B-cells inhibitor, alpha), MEFs (Mouse embryonic fibroblasts), MnSOD (Manganese superoxide dismutase), NEDD4L (Neural precursor cell expressed developmentally downregulated gene 4-like), PAQR3 (Progestin and adipoQ receptor family member 3), TGF- $\beta 1$ (Transforming growth factor beta 1), VEGF (vascular endothelial growth factor), Zeb1 (Zinc finger E-box-binding homeobox 1).

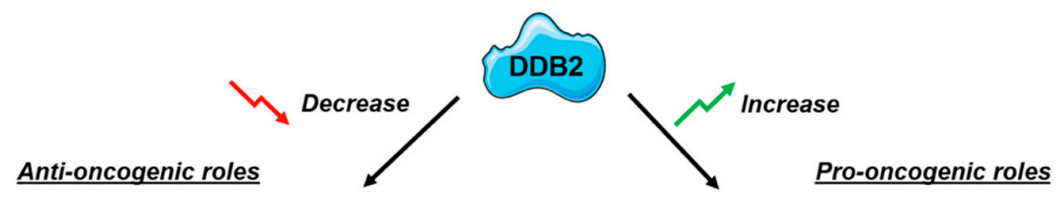

\begin{tabular}{|c|c|}
\hline reast cancer & \\
\hline Migration/invasion & $\begin{array}{l}\text { Activation of IKBa expression } \\
\text { Interaction with TGF } \beta 1 \text { signalling pathw }\end{array}$ \\
\hline Ovarian cancer & \\
\hline Proliferation & Repression of NEDD4L expression \\
\hline $\begin{array}{l}\text { Resistance } \\
\text { to therapy }\end{array}$ & Repression of $\mathrm{Bcl}-2$ expression \\
\hline CSC population & $\begin{array}{l}\text { Repression of ALDH1A1 expression } \\
\text { Activation of IKBa expression }\end{array}$ \\
\hline Colon cancer & \\
\hline EMT & Repression of Snail, Zeb1 expression \\
\hline Angiogenesis & Repression of VEGF expression \\
\hline Prostate c & \\
\hline Proliferation & Degradation of $A R$ \\
\hline
\end{tabular}

\begin{abstract}
Breast cancer
Proliferation Repression of MnSOD expression
\end{abstract}

Gastric cancer

Migration/Invasion Degradation of PAQR3

Figure 3. Identified impacts of the DDB2 protein activity in different solid tumors.

Author Contributions: Writing—original draft preparation, P.G. and G.D.; writing—review and editing, P.G., A.H., A.W., and P.B.; supervision, P.B. and A.H.; project administration, J.-L.M. and A.H. All authors read and approved the final manuscript.

Funding: This research received no external funding.

Conflicts of Interest: The authors declare no conflict of interest. 


\section{Abbreviations}

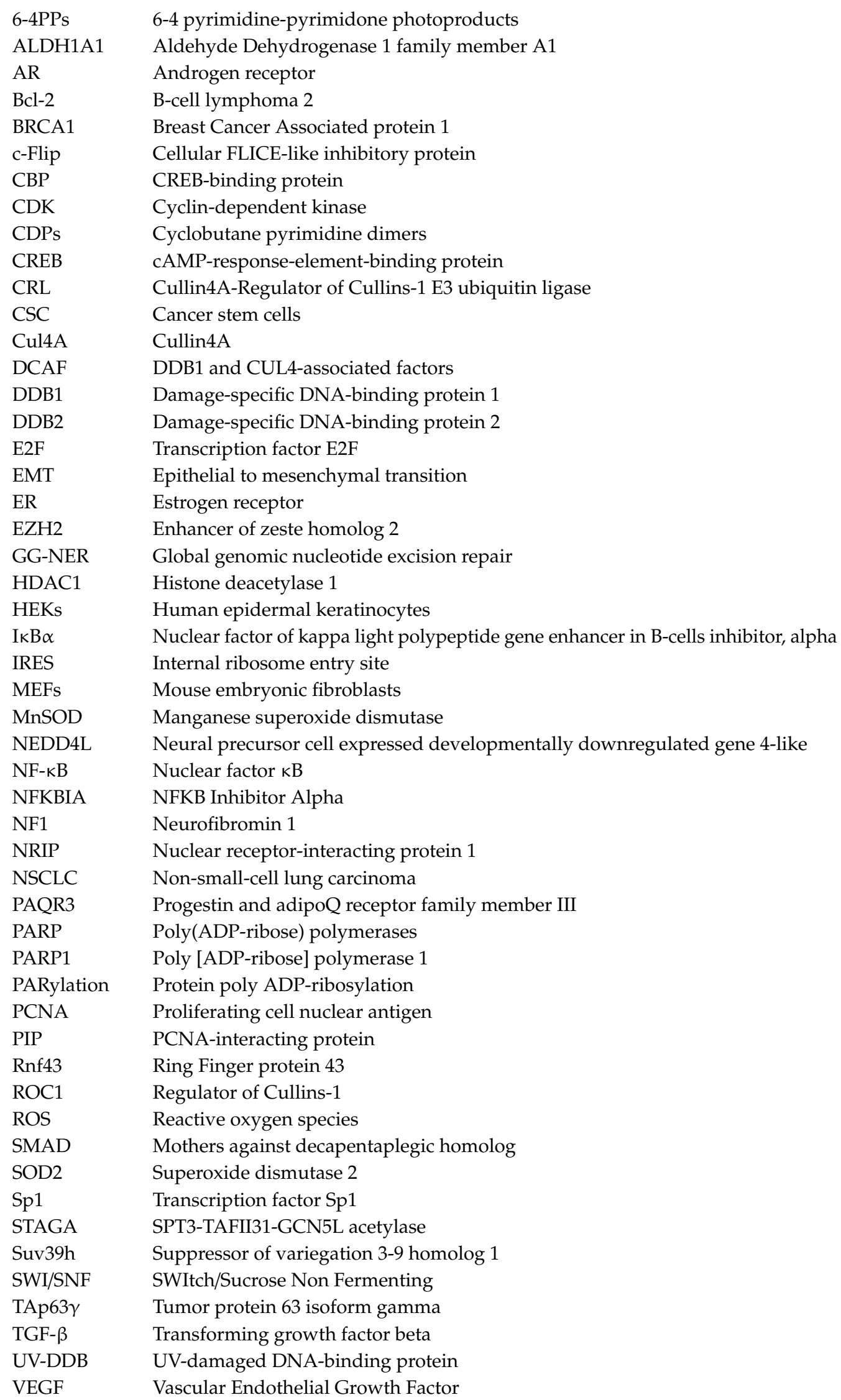


XPC Xeroderma pigmentosum group C

XP-E Xeroderma pigmentosum group E

ZEB1 Zinc finger E-box Binding homeobox 1

\section{References}

1. Tan, T.; Chu, G. p53 Binds and Activates the Xeroderma Pigmentosum DDB2 Gene in Humans but Not Mice. Mol. Cell. Biol. 2002, 22, 3247-3254. [CrossRef]

2. Scrima, A.; Konícková, R.; Czyzewski, B.K.; Kawasaki, Y.; Jeffrey, P.D.; Groisman, R.; Nakatani, Y.; Iwai, S.; Pavletich, N.P.; Thomä, N.H. Structural basis of UV DNA-damage recognition by the DDB1-DDB2 complex. Cell 2008, 135, 1213-1223. [CrossRef]

3. Nag, A.; Bondar, T.; Shiv, S.; Raychaudhuri, P. The xeroderma pigmentosum group E gene product DDB2 is a specific target of cullin 4A in mammalian cells. Mol. Cell. Biol. 2001, 21, 6738-6747. [CrossRef] [PubMed]

4. Liu, J.; Lin, M.; Zhang, C.; Wang, D.; Feng, Z.; Hu, W. TAp63 $\gamma$ enhances nucleotide excision repair through transcriptional regulation of DNA repair genes. DNA Repair 2012, 11, 167-176. [CrossRef] [PubMed]

5. Nichols, A.F.; Itoh, T.; Zolezzi, F.; Hutsell, S.; Linn, S. Basal transcriptional regulation of human damage-specific DNA-binding protein genes DDB1 and DDB2 by Sp1, E2F, N-myc and NF1 elements. Nucleic Acids Res. 2003, 31, 562-569. [CrossRef] [PubMed]

6. Dai, W.; Ma, W.; Li, Q.; Tao, Y.; Ding, P.; Zhu, R.; Jin, J. The 5'-UTR of DDB2 harbors an IRES element and upregulates translation during stress conditions. Gene 2015, 573, 57-63. [CrossRef] [PubMed]

7. Luijsterburg, M.S.; Lindh, M.; Acs, K.; Vrouwe, M.G.; Pines, A.; van Attikum, H.; Mullenders, L.H.; Dantuma, N.P. DDB2 promotes chromatin decondensation at UV-induced DNA damage. J. Cell Biol. 2012, 197, 267-281. [CrossRef] [PubMed]

8. Cazzalini, O.; Perucca, P.; Mocchi, R.; Sommatis, S.; Prosperi, E.; Stivala, L.A. DDB2 association with PCNA is required for its degradation after UV-induced DNA damage. Cell Cycle Georget. Tex 2014, 13, 240-248. [CrossRef]

9. Perucca, P.; Sommatis, S.; Mocchi, R.; Prosperi, E.; Stivala, L.A.; Cazzalini, O. A DDB2 mutant protein unable to interact with PCNA promotes cell cycle progression of human transformed embryonic kidney cells. Cell Cycle 2015, 14, 3920-3928. [CrossRef]

10. Marteijn, J.A.; Lans, H.; Vermeulen, W.; Hoeijmakers, J.H.J. Understanding nucleotide excision repair and its roles in cancer and ageing. Nat. Rev. Mol. Cell Biol. 2014, 15, 465-481. [CrossRef]

11. Scrima, A.; Fischer, E.S.; Lingaraju, G.M.; Böhm, K.; Cavadini, S.; Thomä, N.H. Detecting UV-lesions in the genome: The modular CRL4 ubiquitin ligase does it best! FEBS Lett. 2011, 585, 2818-2825. [CrossRef] [PubMed]

12. Lan, L.; Nakajima, S.; Kapetanaki, M.G.; Hsieh, C.L.; Fagerburg, M.; Thickman, K.; Rodriguez-Collazo, P.; Leuba, S.H.; Levine, A.S.; Rapić-Otrin, V. Monoubiquitinated histone H2A destabilizes photolesion-containing nucleosomes with concomitant release of UV-damaged DNA-binding protein E3 ligase. J. Biol. Chem. 2012, 287, 12036-12049. [CrossRef] [PubMed]

13. Lans, H.; Marteijn, J.A.; Vermeulen, W. ATP-dependent chromatin remodeling in the DNA-damage response. Epigenetics Chromatin 2012, 5, 4. [CrossRef] [PubMed]

14. Tang, J.; Chu, G. Xeroderma pigmentosum complementation group E and UV-damaged DNA-binding protein. DNA Repair 2002, 1, 601-616. [CrossRef]

15. Zhao, Q.; Wang, Q.E.; Ray, A.; Wani, G.; Han, C.; Milum, K.; Wani, A.A. Modulation of nucleotide excision repair by mammalian SWI/SNF chromatin-remodeling complex. J. Biol. Chem. 2009, 284, 30424-30432. [CrossRef] [PubMed]

16. Kattan, Z.; Marchal, S.; Brunner, E.; Ramacci, C.; Leroux, A.; Merlin, J.L.; Domenjoud, L.; Dauça, M.; Becuwe, P. Damaged DNA binding protein 2 plays a role in breast cancer cell growth. PLoS ONE 2008, 3 , e2002. [CrossRef]

17. Yan, Y.; Zhang, X.; Legerski, R.J. Artemis interacts with the Cul4A-DDB1DDB2 ubiquitin E3 ligase and regulates degradation of the CDK inhibitor p27. Cell Cycle 2011, 10, 4098-4109. [CrossRef]

18. Sharma, P.; Nag, A. CUL4A ubiquitin ligase: A promising drug target for cancer and other human diseases. Open Biol. 2014, 4, 130217. [CrossRef] 
19. Yoon, T.; Chakrabortty, A.; Franks, R.; Valli, T.; Kiyokawa, H.; Raychaudhuri, P. Tumor-prone phenotype of the DDB2-deficient mice. Oncogene 2005, 24, 469-478. [CrossRef]

20. Bagchi, S.; Raychaudhuri, P. Damaged-DNA Binding Protein-2 Drives Apoptosis Following DNA Damage. Cell Div. 2010, 5, 3. [CrossRef]

21. Chen, H.-H.; Fan, P.; Chang, S.W.; Tsao, Y.P.; Huang, H.P.; Chen, S.L. NRIP/DCAF6 stabilizes the androgen receptor protein by displacing DDB2 from the CUL4A-DDB1 E3 ligase complex in prostate cancer. Oncotarget 2017, 8, 21501-21515. [CrossRef] [PubMed]

22. Yang, H.; Liu, J.; Jing, J.; Wang, Z.; Li, Y.; Gou, K.; Feng, X.; Yuan, Y.; Xing, C. Expression of DDB2 Protein in the Initiation, Progression, and Prognosis of Colorectal Cancer. Dig. Dis. Sci. 2018, 63, 2959-2968. [CrossRef] [PubMed]

23. Liu, J.; Li, H.; Sun, L.; Feng, X.; Wang, Z.; Yuan, Y.; Xing, C. The Differential Expression of Core Genes in Nucleotide Excision Repair Pathway Indicates Colorectal Carcinogenesis and Prognosis. BioMed Res. Int. 2018, 2018, 9651320. [CrossRef] [PubMed]

24. Stoyanova, T.; Roy, N.; Bhattacharjee, S.; Kopanja, D.; Valli, T.; Bagchi, S.; Raychaudhuri, P. p21 cooperates with DDB2 protein in suppression of ultraviolet ray-induced skin malignancies. J. Biol. Chem. 2012, 287, 3019-3028. [CrossRef] [PubMed]

25. Bommi, P.V.; Ravindran, S.; Raychaudhuri, P.; Bagchi, S. DDB2 regulates Epithelial-to-Mesenchymal Transition (EMT) in Oral/Head and Neck Squamous Cell Carcinoma. Oncotarget 2018, 9, 34708-34718. [CrossRef] [PubMed]

26. Han, C.; Zhao, R.; Liu, X.; Srivastava, A.; Gong, L.; Mao, H.; Qu, M.; Zhao, W.; Yu, J.; Wang, Q.E. DDB2 suppresses tumorigenicity by limiting the cancer stem cell population in ovarian cancer. Mol. Cancer Res. 2014, 12, 784-794. [CrossRef] [PubMed]

27. De Sousa, J.F.; Torrieri, R.; Serafim, R.B.; Di Cristofaro, L.F.; Escanfella, F.D.; Ribeiro, R.; Zanette, D.L.; Paçó-Larson, M.L.; da Silva, W.A., Jr.; Tirapelli, D.P.; et al. Expression signatures of DNA repair genes correlate with survival prognosis of astrocytoma patients. Tumor Biol. 2017, 39, 1010428317694552. [CrossRef] [PubMed]

28. Becuwe, P.; Ennen, M.; Klotz, R.; Barbieux, C.; Grandemange, S. Manganese superoxide dismutase in breast cancer: From molecular mechanisms of gene regulation to biological and clinical significance. Free Radic. Biol. Med. 2014, 77, 139-151. [CrossRef]

29. Zhao, R.; Cui, T.; Han, C.; Zhang, X.; He, J.; Srivastava, A.K.; Yu, J.; Wani, A.A.; Wang, Q.E. DDB2 modulates TGF- $\beta$ signal transduction in human ovarian cancer cells by downregulating NEDD4L. Nucleic Acids Res. 2015, 43, 7838-7849. [CrossRef]

30. Chang, S.W.; Su, C.H.; Chen, H.H.; Huang, C.W.; Tsao, L.P.; Tsao, Y.; Chen, S.L. DDB2 is a novel AR interacting protein and mediates AR ubiquitination/degradation. Int. J. Biochem. Cell Biol. 2012, 44, 1952-1961. [CrossRef]

31. Huang, S.; Fantini, D.; Merrill, B.J.; Bagchi, S.; Guzman, G.; Raychaudhuri, P. DDB2 Is a Novel Regulator of Wnt Signaling in Colon Cancer. Cancer Res. 2017, 77, 6562-6575. [CrossRef] [PubMed]

32. Zou, N.; Xie, G.; Cui, T.; Srivastava, A.K.; Qu, M.; Yang, L.; Wei, S.; Zheng, Y.; Wang, Q.E. DDB2 increases radioresistance of NSCLC cells by enhancing DNA damage responses. Tumour Biol. 2016, 37, 14183-14191. [CrossRef] [PubMed]

33. Zhao, L.; Si, C.-S.; Yu, Y.; Lu, J.-W.; Zhuang, Y. Depletion of DNA damage binding protein 2 sensitizes triple-negative breast cancer cells to poly ADP-ribose polymerase inhibition by destabilizing Rad51. Cancer Sci. 2019. [CrossRef] [PubMed]

34. Zhao, R.; Han, C.; Eisenhauer, E.; Kroger, J.; Zhao, W.; Yu, J.; Selvendiran, K.; Liu, X.; Wani, A.A.; Wang, Q.E. DNA Damage-Binding Complex Recruits HDAC1 to Repress Bcl-2 Transcription in Human Ovarian Cancer Cells. Mol. Cancer Res. 2014, 12, 370-380. [CrossRef]

35. Itoh, T.; O'Shea, C.; Linn, S. Impaired regulation of tumor suppressor p53 caused by mutations in the xeroderma pigmentosum DDB2 gene: Mutual regulatory interactions between p48(DDB2) and p53. Mol. Cell. Biol. 2003, 23, 7540-7553. [CrossRef]

36. Sun, N.K.; Sun, C.L.; Lin, C.H.; Pai, L.M.; Chao, C.C. Damaged DNA-binding protein 2 (DDB2) protects against UV irradiation in human cells and Drosophila. J. Biomed. Sci. 2010, 17, 27. [CrossRef]

37. Barbieux, C.; Bacharouche, J.; Soussen, C.; Hupont, S.; Razafitianamaharavo, A.; Klotz, R.; Pannequin, R.; Brie, D.; Bécuwe, P.; Francius, G.; et al. DDB2 (damaged-DNA binding 2) protein: A new modulator of nanomechanical properties and cell adhesion of breast cancer cells. Nanoscale 2016, 8, 5268-5279. [CrossRef] 
38. Qiao, S.; Guo, W.; Liao, L.; Wang, L.; Wang, Z.; Zhang, R.; Xu, D.; Zhang, Y.; Pan, Y.; Wang, Z.; et al. DDB2 is involved in ubiquitination and degradation of PAQR3 and regulates tumorigenesis of gastric cancer cells. Biochem. J. 2015, 469, 469-480. [CrossRef]

39. Cui, T.; Srivastava, A.K.; Han, C.; Wu, D.; Wani, N.; Liu, L.; Gao, Z.; Qu, M.; Zou, N.; Zhang, X.; et al. DDB2 represses ovarian cancer cell dedifferentiation by suppressing ALDH1A1. Cell Death Dis. 2018, 9, 561. [CrossRef]

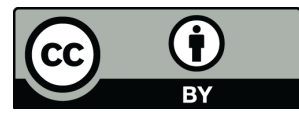

(C) 2019 by the authors. Licensee MDPI, Basel, Switzerland. This article is an open access article distributed under the terms and conditions of the Creative Commons Attribution (CC BY) license (http://creativecommons.org/licenses/by/4.0/). 